\title{
VIOLAÇÃO DE DIREITOS HUMANOS NO SISTEMA PENITENCIÁRIO
}

\section{VIOLATION OF HUMAN RIGHTS IN THE PRISON SYSTEM}

\author{
Felipe da Silva Rodrigues* \\ Fabiana Delgado** \\ Maria Geralda de Miranda*** \\ Reis Friede****
}

Resumo: $O$ presente trabalho tem por objetivo demonstrar a ocorrência de violação dos Direitos Humanos no sistema prisional, praticada como objeto de correção ou abuso de poder. Apresenta um pouco do contexto histórico e da evolução dos Direitos Humanos e do Princípio da Dignidade Humana. A violação dos direitos humanos fundamentais cometida por membros do sistema penitenciário constituí uma afronta aos princípios constitucionais e à Declaração Universal dos Direitos Humanos. As vítimas são os presos e seus parentes, geralmente pessoas pobres sem influência econômica, social ou política, que são detidos como acusados ou suspeitos de crimes e que geralmente têm dificuldade em acessar a justiça por falta de informação e / ou instrução. As violações dos direitos humanos têm inibido o desenvolvimento de investigações criminais científicas. Várias regras argumentam que os presos devem ser tratados com dignidade e respeito e não devem ser submetidos a tortura ou tratamento cruel. A prática de violação de direitos gera descrença na recuperação de presos, nas instituições e nas políticas de segurança pública. $O$ treinamento e o aprimoramento dos profissionais de segurança prisional são importantes para que eles percebam que são garantidores de direitos, que devem cumprir e fazer cumprir as leis, tratados e convenções de Direitos Humanos. A prisão deve ser um ambiente humanizado, com respeito aos direitos fundamentais, e a punição não deve ser uma maneira de agravar o sofrimento do prisioneiro. Deve haver maior participação e controle social junto às ouvidorias e corregedorias. É importante que exista confiança social nos órgãos e agentes penitenciários, a fim de serem mais eficazes na prevenção de crimes e na proteção dos direitos dos presos.

Palavras-chave: Direitos Humanos, Dignidade da pessoa Humana, Direitos do preso, Violação, Sistema penitenciário.

\footnotetext{
* Servidor do Poder Judiciário Federal, ocupante do cargo de Agente de Segurança Judiciária, ExFuzileiro Naval, Ex-Bombeiro Militar, graduado em Fisioterapia pela UNESA, Bacharel em Direito pela UNISUAM, pós-graduado em Segurança Pública, interesse nas áreas de Direitos Humanos, Segurança Pública e Direito do Trabalho.

** Mestranda em Desenvolvimento Local pelo Programa de Pós-Graduação em Desenvolvimento Local do Centro Universitário Augusto Motta, UNISUAM.

*** Pós-doutora em políticas públicas pela UERJ e Pesquisadora do Programa de PósGraduação em

Desenvolvimento Local do Centro Universitário Augusto Motta, UNISUAM.

**** Reis Friede é Desembargador Federal. Mestre e Doutor em Direito e Professor e Pesquisador do Programa de

Mestrado em Desenvolvimento Local do Centro Universitário Augusto Motta (UNISUAM). Correio eletrônico:

reisfriede@hotmail.com.
} 
Abstract: This paper aims to demonstrate the occurrence of violation of Human Rights within the prison system, practiced as an object of correction or abuse of power. It presents a little of the historical context and evolution of Human Rights and the Principle of Human Dignity. The violation of fundamental human rights committed by members of the prison system constituted an affront to constitutional principles and the Universal Declaration of Human Rights. The victims are the prisoners and their relatives, usually poor people with no economic, social or political influence, who are detained as accused or suspected of crimes and who generally have difficulty accessing justice for lack of information and / or instruction. Human rights violations have been inhibiting the development of scientific criminal investigation. Several rules argue that prisoners should be treated with dignity and respect and should not be subjected to torture or cruel treatment. The practice of this violation leads to disbelief in the recovery of the prisoner, institutions and public security policies. Training and improvement of prison security professionals is important for them to realize that they are rights guarantors, who must comply with and enforce human rights laws, treaties and conventions. Prison should be a humanized environment with respect for Fundamental Rights and punishment should not be a way to aggravate the suffering of the prisoner. There must be greater participation and social control with the ombudsmen and Internal Affairs. It is important that there is societal trust in prison organs and agents in order to be more effective in preventing crimes and violating the rights of prisoners.

Keywords: Human Rights, Dignity of the Human Person, Rights of the Prisoner, Violation, Penitentiary System. 


\section{INTRODUÇÃO}

O presente trabalho é um estudo na área dos Direitos Humanos, que tem por objetivo demonstrar a ocorrência de violação de direitos fundamentais dentro do sistema penitenciário. $\mathrm{O}$ assunto é abordado de forma ampla, porém objetiva, com uma breve análise histórica dos direitos humanos e do reconhecimento da dignidade da pessoa humana. Aponta-se as condutas violadoras de direitos praticadas no sistema prisional e as características das vítimas mais frequentes, bem como as normas e políticas públicas que objetivam acabar com a violação de direitos fundamentais dentro do sistema penitenciário.

O estudo objetiva também demonstrar a necessidade de uma formação e aperfeiçoamento dos profissionais do setor direcionada para a proteção e garantia dos direitos fundamentais do indivíduo como forma de prevenir e combater a violação de direitos básicos da pessoa. Concluímos, apontando a necessidade de uma participação social onde o cidadão, além de acreditar no trabalho dos órgãos envolvidos, deve cobrar qualidade, resultados e transparência nas ações realizadas, podendo ainda contribuir com denúncias de desvios de conduta e de abusos de poder realizadas junto às Ouvidorias e Corregedorias. Mostra-se que é preciso direcionar ações para um problema específico, juntamente com um esforço de repensar, redirecionar e intensificar as ações de prevenção e combate da tortura e violação de direitos cometida no sistema carcerário.

Embasado em pesquisa bibliográfica, aborda de forma descritiva o tema a partir de fontes disponíveis nas bibliotecas e na internet, tais como: livros, artigos, peças processuais, doutrina e legislação.

Os direitos fundamentais são garantidos e defendidos para todos os povos em qualquer tempo, possuem caráter inviolável, atemporal e universal, estando diretamente ligados a uma história de lutas contra injustiças. Os direitos fundamentais advêm da própria natureza humana, sendo conhecidos também como direitos humanos, direitos da pessoa humana, direitos dos homens, direitos individuais, direitos do homem e do cidadão, direitos naturais, entre outros. 
Nossa Carta Magna de 1988 prevê por todo seu texto que os direitos fundamentais devem ser garantidos pelo Estado e por qualquer de seus poderes devendo ser respeitado por todos.

Necessário apontar que a transformação da humanidade foi marcada por importantes momentos históricos como a revolução industrial e a, que consolidaram os ideais de igualdade entre os homens, mais especificamente na positivação de direitos civis e políticos. Assim, imprescindível a análise histórica dos direitos humanos como garantia fundamental do homem reconhecido como sujeito de direitos.

\section{HISTÓRICO DIREITOS HUMANOS E A DIGNIDADE DA PESSOA HUMANA}

A Dignidade Humana é composta por um conjunto de direitos existenciais compartilhados por todos os homens, em igual proporção.

Sarlet (2015) destaca que "a ideia de dignidade da pessoa humana, resulta da convergência de diversas doutrinas e concepções de mundo que vêm sendo construídas desde longas datas na cultura ocidental".

Comparato (2010) e Aragão (2001) apontam que as primeiras concepções de direito fundamental repousavam na idade antiga e média, ora difundida no divino (cristianismo), e ora na natureza racional. Surgiu daí a concepção do direito natural de que certas garantias eram inerentes ao homem. Algumas destas leis naturais materializaram-se em documentos como o Código de Hamurabi, a Lei das XII Tábuas e as Leis Mosaicas.

Em 1879 foi descoberto nas ruínas da Babilônia, o cilindro de Ciro, um cilindro de argila, em língua acádica e com escrita cuneiforme, que passou a ser considerado por muitos como a primeira carta de direitos humanos. O cilindro continha as declarações do Rei Ciro datadas de 539 a.C., que determinava o livramento dos homens da escravidão e estabelecia a igualdade racial e o direito a escolha de uma religião (MIGUEL, 2016). 
Castilho (2012) destaca que para melhor compreender a evolução história dos Direitos Humanos, é necessário destacar alguns acontecimentos passados que contribuíram para a classificação dos direitos fundamentais em dimensões.

Helisane Mahlke (2017, p. 26) aponta que os Direitos Humanos podem ser classificados em 6 dimensões que contribuíram para o seu surgimento.

Em 1215 houve a elaboração da Carta Magna, documento de grande importância no processo da Declaração de Direitos Humanos. A carta tinha o escopo de proteger o povo das arbitrariedades do rei João da Inglaterra, e previa o direito de a igreja ficar livre da interferência do governo, o direito de liberdade para que todos cidadãos pudessem possuir e herdar propriedades, e também de proteção contra impostos excessivos. A Carta Magna buscava a liberdade e a proteção do indivíduo contra os abusos do Estado.

Em 1689, surgiu o Bill of Rights, fruto da "Revolução Gloriosa" ocorrida na Inglaterra no mesmo período, que retirava parte do poder do monarca, transferindo esse poder para o Parlamento, como representantes do povo (MAHLKE, 2017, p. 13).

Em 1776 com o surgimento da Declaração de Independência dos Estados Unidos, os direitos previstos na Carta Magna e no Bill of Rights foram reconhecidos e fortalecidos. A importância histórica da Declaração de Independência é por ser o primeiro documento político que reconhece, a par da legitimidade da soberania popular, a existência de direitos inerentes a todo ser humano, independentemente das diferenças de sexo, raça, religião, cultura ou posição social (COMPARATO, 2010, p. 119).

Outro marco importante foi a Revolução Francesa, considerada a mais notória delas. Teve como objetivos fazer com que todos os franceses fossem iguais perante a lei, melhorar as condições econômicas, separar o Estado da Igreja e estabelecer as divisões dos poderes. Silva (2017) destaca que a revolução contribuiu para a aprovação da Declaração dos Direitos do Homem e do Cidadão em 1789, trazendo a ideia de liberdade e igualdade da Declaração de Independência dos Estados Unidos e ampliando os direitos com a ideia de fraternidade. No entendimento de Fabio Konder Comparato, o artigo I da Declaração de Independência Americana "é o registro de nascimento dos Direitos Humanos na 
história", vindo a consolidar a ideia de igualdade entre os homens, também presente na Declaração dos Direitos do Homem e do Cidadão de 1789 (COMPARATO, 2010, p. 62)

Piovesan (2014) assinala que esses documentos (a Carta Magna, o Bill of Rights, a Declaração de Independência dos Estados Unidos e a Declaração dos Direitos do Homem e do Cidadão), contribuíram para o reconhecimento dos direitos fundamentais de primeira dimensão (liberdades públicas, direitos civis e políticos).

Com a Revolução Francesa e a Revolução Industrial, surgiram outros documentos como as Constituições Mexicana de 1917, que foi a primeira a reconhecer os direitos dos Trabalhadores; a Constituição Alemã de Weimar em 1919, que consagrava uma série de direitos como educação, trabalho, saúde e liberdade religiosa; e ainda a Constituição do Brasil de 1934 e o Tratado de Versalhes, que juntos, deram origem aos direitos fundamentais de segunda dimensão (direitos sociais, culturais e econômicos que nasceram com o princípio da igualdade). (MAHLKE, 2017, p. 28).

Já os direitos fundamentais de terceira dimensão objetivam a fraternidade e a solidariedade, são direitos de proteção, comunicação e do meio ambiente, de forma difuso e coletiva. Buscam a proteção do meio ambiente e de grupos humanos como a infância, a juventude, a família, o povo e a nação (SARLET, 2011, p. 48).

Mahlke (2017, p. 28) diz que os direitos de quarta dimensão são aqueles advindos da afirmação de uma cidadania global, necessidade emergente no mundo atual por causa do processo de transnacionalização de bens, valores, informação e, principalmente, das próprias pessoas. Engloba as transformações advindas da ciência, da tecnologia e informação, assegurando o direito à dignidade humana em face das transformações e modificações da sociedade globalizada.

Os direitos de quinta dimensão seriam aqueles relativos ao direito à paz e que pertencem a toda humanidade. Já os direitos de sexta dimensão seriam aqueles relacionados à bioética, à manipulação genética e demais direitos tocados pelo avanço das pesquisas científicas e pela evolução tecnológica.

Voltando ao pós Segunda Guerra Mundial, importante destacar a Carta das Nações Unidas, como resultado da Conferência de São Francisco e do surgimento da 
Organização das Nações Unidas - ONU em 1945, que marcam uma nova fase na proteção dos Direitos Humanos (MAHLKE, 2017, p. 16).

Em 1948 foi promulgada a Declaração Universal de Direitos Humanos, que trouxe a ideia de direitos universais e confirmou a tríade liberdade, igualdade e fraternidade. Trata-se de um instrumento pelo qual os Estados-Nação estão comprometidos a observarem os direitos comuns a todos os homens. Essa declaração constitui o principal documento de proteção aos direitos humanos, sobretudo porque é a partir dela que o indivíduo passa a ser considerado sujeito de direitos no plano internacional (ORGANIZAÇÃO DAS NAÇÕES UNIDAS, 1948).

Outros documentos internacionais importantes foram o Pacto dos Direitos Civis e Políticos e o Pacto dos Direitos Sociais e Econômicos em 1966, e ainda a Convenção Americana de Direitos Humanos, Pacto de San José da Costa Rica em 1969, que visavam uma tentativa política de reafirmar direitos que eram violados pelos mesmos dirigentes que diziam defendê-los.

Em 1993, a Declaração de Viena (Conferência Mundial dos Direitos Humanos) demonstrou grande apoio internacional à promoção e fortalecimento da democracia e dos direitos humanos, realçando uma concepção contemporânea dos Direitos Humanos caracterizado pela universalidade e indivisibilidade dos direitos humanos.

Ricardo Castilho (2012) explica que a concepção mais atual de Direitos Humanos está expressa na Declaração Universal dos Direitos Humanos, segundo a qual, os Direitos Humanos pertencem à pessoa humana, não precisando de lei para regulamentá-lo. Para Castilho, "o direito humano é o respeito que cada pessoa deve ter com o próximo, devendo ter sempre em mente que cada pessoa é um ser, devendo todos serem tratados com dignidade." (CASTILHO, 2012, p. 11-12).

No plano nacional, os Direitos Humanos foram expressamente internalizados e elevados a um status constitucional, dando a estes direitos a nomenclatura de direitos e garantias fundamentais, estando inserido neste rol aquele que é considerado o princípio basilar de todo o ordenamento jurídico e um dos fundamentos da República Federativa do Brasil, a Dignidade da Pessoa Humana. 
O Princípio da Dignidade da Pessoa Humana, consagrado no artigo 10, inciso III da Constituição da República de 1988, previsto no rol das garantias fundamentais, é considerado um princípio máximo do Estado Democrático de Direito. Esse princípio visa um valor espiritual, moral, inerente a pessoa, ou seja, todo e quaisquer ser humano é dotado dessas condições.

A dignidade humana é um direito fundamental de todo indivíduo, destina-se a assegurar sem qualquer distinção, o respeito à integridade física e moral previsto no artigo 50, XLIX da CF/88. Cabe ao Estado, representado por seus agentes a obrigação de proporcionar dignidade a seus cidadãos.

Os Direitos Humanos são os direitos e liberdades básicas de todas as pessoas, fincados no Princípio do respeito, que segundo a obra "Fundamentação da metafísica dos costumes" de Immanuel Kant, possui características como a privacidade, veracidade e autonomia da vontade (KANT, 2009). A dignidade humana está intimamente ligada ao respeito, princípio que deve ser observado a todas as pessoas. Esse princípio é fruto de conquistas que atravessaram a história da humanidade como por exemplo a Segunda Guerra Mundial onde ocorreu sem limites grande desrespeito ao ser humano.

O objetivo dos Direitos Humanos é preservar a dignidade da pessoa, protegendo-a contra o arbítrio do Estado e proporcionar a melhor condição de vida para permitir o livre desenvolvimento das atividades humanas. Toda pessoa é um ser moral e racional, são universais, logo, deve ser aplicado a todos; sem discriminação de raça, cor, sexo ou religião.

O Princípio da Dignidade da Pessoa Humana, traz consigo uma gama de direitos e atributos necessários para sustentar a dignidade da vida em sociedade, tendo como elementos básicos para a sobrevivência: o saneamento básico; a saúde; o emprego; a segurança pública; entre outros, todos essenciais para a garantia fundamental em nossa constituição.

Segundo Castilho (2012, p. 12-14) existe grande discussão sobre a terminologia correta para designar Direitos Humanos, sendo aceito e utilizado várias expressões tais como: direitos individuais, direitos humanos, direito público 
subjetivo, liberdades fundamentais, liberdade pública, direitos fundamentais do homem ou direitos humanos fundamentais.

Castilho (2012, p. 106-108) relata que nossa constituição é um dos documentos mais democráticos do mundo e, apesar disso, carecemos muito de cidadania pois, em termos de direitos humanos, tudo o que está previsto na Carta Magna é muito diferente da realidade. A prática e teoria guardam ainda enorme distância entre si.

Existem duas concepções quanto a natureza dos direitos da pessoa humana. Uma concepção tradicional, aponta que a natureza humana teve sua origem no jus naturalismo na Grécia antiga, onde os gregos acreditavam que o poder adivinha do cosmos (deuses), passando para uma visão mais clássica de que o direito natural seria produto da própria razão humana. Na concepção tradicional, os direitos naturais (Ius naturalismo) independem de legislação, são inerentes a pessoa humana e necessários para a sobrevivência, não foram criados pelo Estado, que apenas os reconheceu como direitos preexistentes e decorrentes da própria condição humana.

Numa segunda concepção, são direitos positivados (Ius positivismo), estabelecidos em lei, que só existem na medida em que são incorporados ao direito positivo de um determinado Estado.

Mahlke (2017, p. 10) aponta que os "Direitos Humanos podem ser considerados como um conjunto de valores comuns à humanidade, entendidos individual ou coletivamente, considerados inerentes à natureza humana e, portanto, não cabe ao direito constituí-los, mas apenas declará-los, são inalienáveis e imprescritíveis por princípio".

Os Direitos Humanos compreendem a cidadania, que conforme explicado por Mahlke:

É um conjunto de direitos que confere a possibilidade de participar ativamente da vida política e do governo. A cidadania implica a convivência em uma ordem democrática, em que o indivíduo se vê integrado ao meio social, goza de participação da vida pública de seu Estado e tem, por ele e pelos demais, sua dignidade respeitada. A cidadania compreende o exercício de direitos e deveres fundamentais, que lhe permitem existir, desenvolverse e participar plenamente da vida, associando-se às características naturais do ser humano e os meios de que este pode se valer para preservá-la no âmbito da organização social (MAHLKE, 2017, p. 158). 


\section{DIREITOS HUMANOS NO SISTEMA PRISIONAL}

Nosso país está entre as democracias mais influentes nos assuntos regionais e globais, mas continua a enfrentar desafios sérios de direitos humanos.

A Declaração Universal dos Direitos Humanos, proclamada em 10 de dezembro de 1948 pela Assembleia Geral das Nações unidas (ONU), possui a ideia central de garantir um conjunto básico de direitos e liberdades válidos em qualquer território, independentemente de sua organização política.

No entendimento de Comparato (2010) a Declaração Universal de Direitos Humanos de 1948, possui em seus 30 artigos o objetivo principal de evitar que o ser humano seja tratado como objeto descartável, além de procurar criar condições concretas para evitar a repetição de fatos que marcaram a história da humanidade.

É notório a existência de desigualdade social da população, inclusive no sistema carcerário. Não é de hoje que estudos como o Levantamento Nacional de Informações Penitenciarias (INFOPEN), demonstram que a maior parte da população carcerária é de pessoas negras ou pardas, de baixa renda, com pouco estudo e geralmente morador de comunidades e periferias. Esse também é o perfil de quem mais sofre violação dos seus direitos básicos como pessoa dentro do sistema carcerário, seja através de um tratamento verbal inadequado ou pela privação de exercer seus direitos mais básicos como pessoa (BRASIL, 2019).

0 artigo $5^{\circ}$ de nossa Constituição Federal resguarda o ser humano pouco importando se honesto ou desonesto, visto que os direitos humanos vestem todos os indivíduos, assim foram concebidos e nesse prisma devem ser observados (NUCCI, 2016, p. 55).

Nossa Constituição Federal determina em seu artigo 30 , inciso XLI, que "Constituem objetivos fundamentais da República Federativa do Brasil: promover o bem de todos, sem preconceitos de origem, raça, sexo, cor, idade e quaisquer outras formas de discriminação"; e no Artigo. 50, inciso XLI, que "a lei punirá qualquer discriminação atentatória dos direitos e liberdades fundamentais".

A pena de privação da liberdade é o recurso utilizado pelo Estado com objetivo de punir e ressocializar aqueles que cometeram crimes. O objetivo do 
Estado é manter a convivência em sociedade pacífica, bem como proteger certos bens jurídicos. Assim, quando uma pessoa é presa, o único direito fundamental que deve ser restrito pelo Estado é o direito à liberdade, sendo a pessoa retirada do convívio em sociedade como forma de se manter e promover a defesa social.

$O$ principal objetivo é recuperar e reintegrar o detento à sociedade, conforme previsto no artigo $1^{0}$ da Lei de Execução Penal: "Art. $1^{0}$ - A execução penal tem por objetivo efetivar as disposições de sentença ou decisão criminal e proporcionar condições para harmônica integração social do condenado e do internado." (BRASIL, 1984, não paginado).

Atualmente, fatores éticos, sociais e materiais contribuem para a falência da prisão em seus objetivos punitivo e ressocializador. Quando uma pessoa é presa e levada ao cárcere, ela sofrerá muitas outras violações de diversos direitos básicos da pessoa humana, além de sofrer preconceitos e humilhações por quem deveria fazer cumprir a lei. Podemos dizer que atualmente a prisão ao invés de ressocializar, acaba por desmoralizar, denigrir e aperfeiçoar o condenado na vida do crime.

Parte da sociedade brasileira enxerga o preso como um criminoso sem correção, a sociedade não acredita na recuperação do detento e acaba por aceitar que o mesmo seja tratado de maneira árdua, em condições desumanas e como animal dentro do cárcere.

O Estado tem o dever de garantir o "mínimo existencial", ou seja, aquilo que é necessário para que uma pessoa tenha assegurada sua sobrevivência a uma vida digna, mesmo estando privada de sua liberdade. O preso condenado enquanto recluso nas penitenciarias é possuidor de direitos, deve ter garantido pelo Estado o mínimo exigido para o respeito à dignidade da pessoa humana e a defesa de seus direitos fundamentais que não foram atingidos pela sentença que o condenou. É por isso, que o Código Penal, em seu o artigo 38, assegura que o preso conserva todos seus direitos não atingidos pela perda da liberdade, impondo-se a todas as autoridades o respeito a sua integridade física e moral. Ainda, o artigo 59, regula que as penas devem ser necessárias e suficientes à reprovação e prevenção do crime (BRASIL, 1940). 
Considerando que vivemos em uma sociedade na qual presenciamos diversos episódios de preconceito e violência, construir uma cultura de direitos humanos é fundamental. Assim como é papel do Estado construir políticas públicas capazes de proporcionar um ambiente de garantia de direitos, que promovam a equidade e a inclusão. A falta de apoio e o desinteresse de governos, a má administração carcerária e o desrespeito à legislação acabam por contribuir com os problemas carcerários como a superlotação, a deterioração da estrutura, a corrupção dos agentes penitenciários, a presença de entorpecentes, rebeliões, motins, dentre outros. Tais problemas demonstram que a finalidade de recuperar o detento está cada vez mais distante.

\subsection{O Agente de Segurança Prisional como Garantidor e Violador de Direitos}

Nucci (2016, p. 52) aponta que as ações do Estado são desenvolvidas por pessoas, os chamados agentes públicos, que estão submetidos a uma série de leis que determinam como devem se comportar e quais são as punições cabíveis em caso de descumprimento dessas obrigações. Assim, o agente de segurança prisional no exercício do cargo ou função, possui obrigação de atuar dentro dos parâmetros estabelecidos em lei, sob pena de incorrer em crime de abuso de autoridade.

A ação do agente de segurança deve ser compreendida como uma atividade desempenhada pelas autoridades legalmente investidas nas funções públicas e dotados de competência para a ação preventiva e repressiva, visando garantir a ordem pública e os direitos da pessoa como cidadão.

Observa-se que quando houver oposição de um infrator, a coercibilidade do ato de polícia irá justificar o emprego da força devendo sempre se manter nos limites da lei utilizando somente a força necessária, onde o excesso praticado poderá configurar abuso de autoridade ou a ocorrência de outros crimes.

A Portaria Interministerial no 4226, de 31 de dezembro de 2010, estabelece diretrizes sobre o uso da força por agentes de segurança pública, considera que o direito à segurança pública deve ser exercido com cidadania demandando a sedimentação de políticas públicas de segurança pautadas no respeito aos direitos 
humanos. A portaria no 4226 prevê ainda que a atividade do agente de segurança deve ser pautada nos princípios da legalidade, necessidade, proporcionalidade, moderação e conveniência (BRASIL, 2011).

Dentro desse contexto, um grande avanço foi a criação das armas não letais para minimizar as mortes e os danos de ferimentos às pessoas, uma vez que estas armas foram projetadas para incapacitar as pessoas temporariamente, com o objetivo de preservar vidas e não causar grande sofrimento nas pessoas.

Como explicado por Mahlke (2017), cidadania implica no exercício de direitos e deveres fundamentais do indivíduo na participação da vida pública de seu Estado com respeito a sua dignidade.

A Constituição Federal de 1988, em seu artigo 144, estabelece que a segurança pública é dever do Estado e direito e responsabilidade de todos, devendo ser exercida para a preservação da ordem pública e da incolumidade das pessoas e do patrimônio. A Constituição refere-se aos órgãos encarregados de assegurar a paz e o bem-estar à sociedade, tendo em vista, que no Estado Democrático de Direito, o grande enfoque da segurança pública destina-se a prevenir a ocorrência de infrações penais.

Nas palavras de Guilherme de Sousa Nucci: "Segurança Pública é justamente a sensação de bem-estar de uma comunidade, certos os seus moradores de que terão uma vida tranquila e pacífica, livres de aborrecimentos trazidos justamente pela convivência com outras pessoas." (NUCCI, 2016, p. 47).

A segurança pública não é atividade ou responsabilidade exclusiva da polícia civil ou militar. Cuida-se de dever de todos, em particular dos órgãos realmente vinculados à Justiça Criminal, como o Ministério Público, a Defensoria Pública e o Judiciário (NUCCI, 2016, p. 48).

A Portaria Interministerial no 4226 regula que é necessário que os membros da segurança pública sejam bem treinados para que não tenham a intenção de matar ou ferir gravemente os agressores e para também tentar diminuir o número de vítimas em confronto.

O Código de Conduta das Nações Unidas, instrumento adotado por intermédio da Resolução n 34/169, de 17 de dezembro de 1979, da Assembleia 
Geral das Nações Unidas, no seu art. $3^{\circ}$, diz: "os funcionários encarregados pela aplicação da lei podem fazer uso da força quando estritamente necessária e até a extensão requerida para o cumprimento do seu dever" (ORGANIZAÇÃO DAS NAÇÕES UNIDAS, 1979, p. 1).

A Resolução da ONU, no 34/169, diz: "o nível de força a ser utilizado poderá ser sempre proporcional ao nível de resistência oferecida. Como o uso da arma de fogo é sempre uma medida extrema, há cinco níveis de força a serem utilizados antes da arma de fogo" (ORGANIZAÇÃO DAS NAÇÕES UNIDAS, 1979, p. 1).

Vejamos:

Nível 1 - Presença física, Nível 2 - Verbalização, Nível 3 - Controle de contato ou controle de mãos livre (técnicas de imobilização e condução), Nível 4 Técnicas de submissão (uso de agentes químicos), Nível 5 - Técnicas defensivas não letais (gases, equipamentos de impacto controlado e imobilizações mais severas) e Nível 6 - Força letal (somente em situações extremas).

Importante frisar que existe uma gama de leis, tratados e normas que protegem o direito do preso enquanto pessoa humana, porém, quando esta gama de procedimentos não é cumprida por quem deveria, acaba por contribuir para o cenário de caos e terror que se tem no sistema penitenciário.

A estrutura do sistema carcerário parece eficaz quando diante de tantas normas existentes, mas na verdade a má aplicação delas é que acaba por produzir um efeito diferente do esperado, ou seja, não atinge os resultados para os quais foram criadas.

Quando um agente do sistema carcerário viola a lei, ele não só viola a dignidade da pessoa humana como coloca uma barreira à eficaz atuação de seu órgão de segurança, o que acaba por trazer efeitos negativos que podem diminuir a confiança da sociedade, isolando a atuação do órgão ou do agente da comunidade, o que acaba por provocar críticas negativas por parte da comunidade nacional e internacional.

A conduta negativa de um agente prisional causa lesão a direitos fundamentais da pessoa, ela pode ser caracterizada por atos comissivos ou 
omissivos, podendo causar ainda danos materiais ou morais a quem foi coagido ou teve sua dignidade violada.

No cenário carcerário as autoridades que deveriam garantir os direitos dos presos parecem atuar com descaso deixando de garantir os direitos à vida e à integridade do indivíduo sobre o qual exercem custódia.

A violação de direitos é praticada em vários setores pelas autoridades responsáveis por sustentar e aplicar a lei. Os agentes de segurança prisional, que são os responsáveis pelo oficio de guarda, vigilância, prevenção e combate à violência, são os mesmos que ignoram os direitos fundamentais do cidadão e acabam por praticar a conduta ilegal através de abusos e arbitrariedades que ferem os direitos fundamentais da pessoa humana.

Não é de hoje que ocorre a violação de direitos humanos, tal pratica sempre existiu, havendo ainda épocas de total retrocessos na garantia desses direitos. Castilho, em sua obra Direitos Humanos, destaca que:

A ditadura militar foi um dos grandes fatores que contribuíram para a baixa evolução dos direitos humanos no Brasil; pois, enquanto em outros países o direito humano era o centro das atenções e, em todo momento, buscava-se aperfeiçoar tais direitos, aqui no Brasil o que se vivia era a ditadura militar, pois o que se via durante esse período era o total desrespeito à pessoa, violando totalmente o direito do cidadão, o que demonstrava um total descaso aos direitos humanos. (CASTILHO, 2012, p. 106).

A Declaração Universal dos Direitos Humanos, importante documento na proteção dos direitos humanos fundamentais, em seu artigo 10, afirma que "todos os seres humanos nascem livres e iguais em dignidade e em direitos. São dotados de razão e de consciência e devem agir uns para com os outros em espírito de fraternidade".

A Declaração traz ainda em seu artigo 30, a vedação a tratamento desumano, cruel ou degradante, como a proibição da prática da tortura.

Conforme a Lei 9.455, de 07 de abril de 1997, que define os crimes de tortura, o artigo 10 , I e II, dispõem que constitui crime de tortura constranger alguém com emprego de violência ou grave ameaça, causando-lhe sofrimento físico ou mental com o fim de obter informação, declaração ou confissão da vítima ou de terceira pessoa; para provocar ação ou omissão de natureza criminosa; e em razão 
de discriminação racial ou religiosa. Como também, submeter alguém, sob sua guarda, poder ou autoridade, com emprego de violência ou grave ameaça, a intenso sofrimento físico ou mental, como forma de aplicar castigo pessoal ou medida de caráter preventivo. (BRASIL, 1997).

Assim, nas palavras de Rabeschini (2014), tortura é a forma mais desumana e degradante a qual um ser humano submete outro, produzindo dor, pânico, desgastes moral e emocional ou desequilíbrio psíquico, provocando lesões, contusões funcionalmente anormais do corpo ou das faculdades mentais, bem como, causando prejuízo a moral. A consumação do crime de tortura se dá tão somente com a simples ocorrência do resultado dor física ou mental; bastando que a vítima sofra, portanto não é necessário que o agente tenha conseguido seu objetivo.

Conforme recente notícia da Procuradoria da República no Pará, datada de 02 de setembro de 2019, O Ministério Público Federal - MPF, aponta que a tortura ainda é utilizada como castigo e como forma de se manter a ordem e disciplina nos ambientes prisionais. A matéria intitulada "MPF recomenda apuração de denúncias de prática de tortura pela Força-Tarefa de Intervenção Penitenciária no PA" mostra relatos que indicam a ocorrência de uma série de violações a normas nacionais e internacionais no tratamento dos presos (PARÁ, 2019).

\subsection{Violação de Direitos do Preso e Ex-Detentos}

O dever do Estado em punir visa manter o equilíbrio e a ordem social. A sanção penal deve buscar a aplicação da pena sem descuidar da função ressocializadora onde o Estado deve garantir o mínimo exigido para o respeito à dignidade da pessoa humana e a defesa de outros direitos fundamentais que não foram atingidos pela sentença condenatória.

O preso, que geralmente integra a classe menos favorecida, já possui diminuída suas expectativas de vida, e ao passar por tratamento desumano e condições precárias dentro do sistema prisional terá aumentado ainda mais seu sentimento de revolta. Com isso, são comuns as rebeliões com brigas de facções rivais que deixam muitos mortos, com presos decapitados, queimados e 
esquartejados. Toda essa situação diminui as chances de recuperação do indivíduo, podendo levar a altos índices de reincidência, uma vez que nossas prisões são ambientes degradantes e violadores dos direitos humanos.

No artigo "Os direitos humanos e as degradantes prisões brasileiras", publicado em 26 de fevereiro de 2019 no site DireitoNet, o autor discute a situação prisional brasileira a partir dos Mutirões do Conselho Nacional de Justiça - CNJ, realizados em 2014, que constatou condições degradantes nos cárceres em diversas regiões do território nacional. Segundo o autor, o CNJ descreve nossas instituições prisionais como chocantes e medievais, que permitem a absoluta e recorrente degradação da dignidade humana (FRIEDE, 2019).

A matéria "Violentas, prisões do Brasil têm imagem internacional de inferno medieval", disponibilizada em 25 de maio de 2019 no Blog do Brasilianismo, aponta recentes repercussões internacionais sobre as prisões brasileiras, bem como as últimas rebeliões e massacres ocorridos nas penitenciarias do país.

Os direitos essenciais do apenado estão presentes em documentos internacionais admitidos pelo ordenamento jurídico, como prevê o Pacto de São José da Costa Rica, Decreto No 678/92 (BRASIL, 1992), a Constituição Federal (BRASIL, 1988) e Lei de Execuções Penais, nº 7.210/84 (BRASIL, 1984).

Vale salientar que a Constituição Federal, estipula em seu artigo 50, incisos III, XLIX e XLVII, respectivamente:

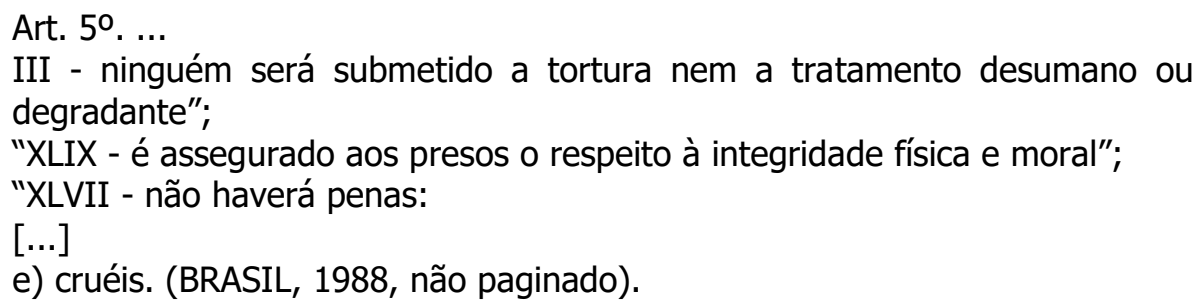

A Lei de Execuções Penais (LEP), Lei 7.210/84, em seu artigo 10, garante a assistência ao preso como dever do Estado, tanto ao preso como ao internado, estendendo-se à figura do egresso. (BRASIL, 1984).

Os artigos 11 e 12 elencam que a assistência ao preso deve fornecer saúde, assistência jurídica, educacional, social e religiosa, alimentação, vestuário e higiene. 
O artigo 40 impõe a todas as autoridades o respeito a integridade física e moral dos condenados e presos provisórios.

Já o artigo 41 aponta 16 incisos que constituem os direitos do preso. Nesse rol se incluem o direito ao trabalho e remuneração, direito à previdência social, direito de exercer atividades intelectuais e artísticas com a finalidade de humanizar o cumprimento da pena.

A Resolução no 14, do Conselho Nacional De Política Criminal E Penitenciária (1994), estabelece as regras mínimas para o tratamento de presos no Brasil, em seu artigo 90 , dispõe que os locais destinados aos presos deverão satisfazer as exigências de higiene, de acordo com o clima, particularmente no que ser refere à superfície mínima, volume de ar, calefação e ventilação. $O$ artigo 10 aponta que os locais devem possuir janelas amplas para permitir a circulação de ar fresco, instalações sanitárias adequadas e instalações para um banho em temperatura adequada ao clima. Porém, não é isso que acontece, vez que na maioria das penitenciarias existe superlotação, fazendo com que o espaço fique reduzido, a limpeza e higiene escassa e a dignidade humana mais uma vez vilipendiada.

Contudo, nada do que é previsto na legislação pertinente acontece, nosso sistema carcerário é visto como forma de pena cruel, uma vez que não há somente o cerceamento da liberdade, mas também tratamento hostil, banal e totalmente desumano.

É certo que a maioria das instalações que abrigam presos são precárias, o que é um verdadeiro choque entre a letra da lei e a realidade.

Nas penitenciarias brasileiras é crescente o número de presos que se amontoam em espaços minúsculo, consequência da superlotação, as carceragens são precárias e sem infraestrutura digna para um ser humano, os presos sofrem maus tratos e acabam sendo vítimas de outras violências quando ocorrem motins, rebeliões e massacres.

Greco (2011, p. 210) aponta que devido a superlotação, existe a figura do preso chamado "preso morcego", que seria o detento que, em razão da impossibilidade de dormir deitado no chão da sua cela, dorme em pé, com seus pulsos amarrados nas grades. Ocorre ainda dos presos se revezam para dormir, ou 
seja, o período de sono é dividido em turnos, por ser impossível que todos, ao mesmo tempo, possam deitar-se para descansar. Tais fatos também configuram um cumprimento cruel e desumano da condenação.

Para o Desembargador Orlando Perri, do Tribunal de Justiça de Mato Grosso, as prisões de hoje são "verdadeiros calabouços medievais". Perri cita que os problemas vivenciados nos presídios vão desde a superlotação que obriga presos a revezarem espaço para dormir no chão do banheiro até celas sem saída de ar e luz. Em uma cela de $18 \mathrm{~m}^{2}$ com capacidade para oito pessoas, foi verificado 30 presos. Afirma ainda, que há indicadores que $80 \%$ são dos encarcerados são reincidentes no estado. Eles saem piores do que entraram porque os presídios estão dominados por organizações criminosas (PERRI, 2019).

As instalações precárias e insalubres do sistema penitenciário são desqualificadas para qualquer finalidade. As penitenciarias são caracterizadas pela violência e superlotação, as celas são quentes, fedorentas e sem a ventilação adequada, não possuem água potável e sanitários higienizados. Os presos convivem com ratos, dormem junto de privadas, possuem higiene limitada, o direito a intimidade é violado, são espancados como forma de punição e correção, ocupam celas superlotadas onde são vítimas uns dos outros, são submetidos a relações sexuais, e estão propensos a doenças sexualmente transmissíveis que se proliferam devido à falta de assistência preventiva e curativa da saúde. Um lugar assim jamais servirá como local para recuperar e ressocializar pessoas.

Conforme o Relatório Nacional sobre a população feminina no Brasil, INFOPEN Mulheres, publicado em 2014 pelo Ministério da Justiça, através do Departamento Penitenciário Nacional, o Brasil possui a quinta maior população carcerária feminina do mundo, onde a maioria das mulheres presas cumpre pena pelo crime de tráfico de drogas. Do total de unidades prisionais no Brasil, apenas 103 são exclusivamente femininas, 239 mistas e 1.070 masculinas, sendo comum o uso de unidades masculinas para abrigarem mulheres (BRASIL, 2014). Assim, é preciso uma mudança urgente de visão sobre o sistema prisional feminino, de modo a compreendermos a essência humana das mulheres encarceradas, de forma a fazer 
valer os direitos garantidos pelas regras de Bangkok aprovadas em 2010. (CONSELHO NACIONAL DE JUSTIÇA, 2016).

Outra violação é a desproporcionalidade da aplicação da pena. As prisões cautelares são mantidas sem o motivo adequado e por mais tempo do que o previsto. Tal questão é mais uma afronta a lei já que a assistência jurídica, como o caso da Defensoria Pública, é direito do preso. Muitos presos que já deveriam estar soltos continuam presos, dessa feita, a pena perdeu seu caráter punitivo e passou a ser uma tortura por manter aquele que teria direito a liberdade em péssimas condições que se encontra o sistema penitenciário por mais tempo que deveria

$\mathrm{O}$ acesso à justiça, mais um direito essencial, também é ameaçado pela burocracia, morosidade, e ineficiência do Estado. A numerosa quantidade de processos e a legislação que não é cumprida impedem uma resposta célere por parte do Estado quanto à garantia desse direito. Existe grande relação intrínseca entre a desigualdade social e o acesso à justiça ou à falta dele. Evidentemente, a garantia constitucional da Defensoria Pública é um elemento importante para promover o acesso à justiça da população menos favorecida.

Os agentes de segurança prisional também praticam agressões físicas e verbais, colocam apelidos em presos e cometem maus tratos físico e/ou psicológico. Nesse contexto, o preso possui direito de ser chamado por seu nome, trata-se de direito da personalidade que abriga a dignidade da pessoa humana. Nossa carta magna, o Código Civil, a LEP e a Resolução no 14 do Conselho Nacional de Política Criminal e Penitenciária que fixa as regras mínimas para o tratamento do preso no brasil, defendem que o preso deve ser chamado por seu nome. Esse tratamento deve ser respeitado por agentes prisionais e todos que possuam contato com o preso no âmbito do sistema penitenciário. $\mathrm{O}$ uso de apelidos, números ou outros nomes ofensivos caracterizam conotação vexatória e humilhante. (BRASIL, 1994).

Bittencourt (2018) aponta que nosso sistema carcerário constitui pura sanção criminal, auxiliando na destruição moral, física e psicológica do preso, que pode vir a apresentar depressão, desespero, ansiedade, raiva, alucinações, claustrofobia e, em médio prazo, psicoses e distúrbios afetivos profundos e irreversíveis. 
Para Soares e Mello (2016), o Estado deveria aplicar medidas políticas socioeducativas com a intenção de melhorar a condição social do preso, vez que não adianta somente castigar o mesmo, mas sim dar ao preso, condições para que eles possam ser reintegrados à sociedade.

Não é difícil perceber que o Estado acaba por cometer um crime diante do apenado, submetendo-o a condições sub-humanas e não se preocupando com o retorno do preso à sociedade.

O ex-detento, somente por já ter sido um recluso do sistema prisional, vai sofrer preconceitos por onde for, ele vai sofrer desprezo e falta de oportunidades, o que acaba por contribuir para sua reincidência.

No entendimento de Soares e Mello (2016) seria um erro considerar que as altas taxas de reincidência demonstram o fracasso do sistema penal, vez que é um indicador insuficiente se comparado com a recaída do ex-detento por conta de outros fatores pessoais e sociais. É por isso, que na maioria das vezes a reinserção em sociedade, nem acontece, sendo notório que a sociedade repudia o retorno do apenado ao meio social, uma vez que sua reinserção será influenciada por seu passado e por sua ficha criminal.

É importante que se analise a ressocialização do apenado através do trabalho, defendendo o embasamento de que todas as pessoas possuem o mesmo grau de dignidade, respeito e observância dos Direitos Humanos nos principais instrumentos normativos e na legislação vigente.

\subsection{Violação de Direitos de Pessoas Ligadas ao Preso}

No sistema prisional não é só o preso que sofre a violação de direitos, seus familiares também sofrem violações e desrespeitos. No caso da mulher, a violação de direitos pode ocorrer numa revista pessoal realizada por um agente do sexo masculino que venha a constranger a pessoa revistada com comportamentos inadequados ou contrariando o artigo 249 do CPP que dispõem: Art. 249. A busca em mulher será feita por outra mulher, se não importar retardamento ou prejuízo da diligência. 
Ocorria também a violação da intimidade, do corpo, da dignidade e da honra da mulher nas revistas intimas realizadas nos estabelecimentos prisionais. Nessas revistas, os familiares de presos precisam se despir e fazer movimentos de agachamento ou abertura de pernas e genitálias para que os agentes prisionais verifiquem se não há nada de proibido no interior de seus órgãos. Este procedimento também era executado em mulheres de idade mais avançada, bem como em crianças e adolescentes (PAULA; SANTANA, 2012).

Vale ressaltar que a constituição federal, em seu artigo $5^{\circ}$, inciso III, sempre proibiu qualquer tratamento desumano ou degradante e $\mathrm{o}$ inciso $\mathrm{X}$ do mesmo artigo proíbe a violação à intimidade, a vida privada e a honra.

Mariath numa análise sobre a revista íntima, denominada até pouco tempo como vexatória, consignou em seu trabalho limites da revista corporal no âmbito do sistema penitenciário o seguinte entendimento:

\begin{abstract}
Tal busca, também conhecida como revista vexatória, consiste no desnudamento do ser humano diante de terceiros, com a exposição das partes íntimas (genitália), chegando, não raras vezes, a ocorrer a penetração do dedo do executor da medida no interior do ânus e/ou da vagina da pessoa revistada, tudo em nome da (in) segurança.

Vê-se, pois, que a revista íntima pode ser direta ou indireta, vez que o simples fato de se despir diante de terceiros, ainda que não haja qualquer contato físico destes com o revistado, gera na imensa maioria das pessoas uma sensação de enorme desconforto, conduzindo-as a imenso constrangimento pela exposição das partes íntimas de seu corpo (MARIATH, 2013, p. 5).
\end{abstract}

Como forma de solucionar tal problema, o Estado buscou a melhor execução de suas normas através de políticas públicas de investimento, como a compra de detectores de metais e aparelhos de raio-x corporal.

Um grande avanço para garantia e defesa desses direitos fundamentais foram leis regionais, como a Lei 15.552/2014 do Estado de São Paulo (2014), que proibiu a realização da revista íntima de visitantes nos estabelecimentos prisionais em todo e qualquer situação, e a Lei 7010/2015 do Estado do Rio de Janeiro (2015), que priorizou o respeito à dignidade humana e proibiu a revista intima, determinando que o procedimento de revista seja realizado por procedimento mecânico através de detectores de metais, aparelhos de raio-x e outras tecnologias que preservem a integridade física, psicológica e moral do revistado. 
Com isso, a Lei $13.271 / 16$, foi a primeira regra de alcance nacional a vedar a revista íntima em todo país. A lei teve seu artigo $3^{\circ}$ vetado, justamente para evitar uma interpretação errônea que pudesses permitir a revista íntima nos estabelecimentos prisionais. (BRASIL, 2016).

Desta forma, atualmente não mais se admite a revista íntima fazendo com que o visitante retire a roupa e realize agachamentos ou saltos, bem como seja submetido a exames clínicos invasivos.

Vale ressaltar, que nossos tribunais já eram unanimes em sustentar que qualquer prova obtida por meio de revista vexatória era considera ilícita, uma vez que feria direitos e garantias individuais como o direito à intimidade, ao respeito à dignidade da pessoa humana e a vedação de tratamento desumano e degradante. Nessa esteira, citamos o julgado da Terceira Câmara Criminal do Tribunal de Justiça do Rio Grande do Sul:

\begin{abstract}
APELAÇÃO CRIME. TRÁFICO ILÍCITO DE DROGAS. TENTATIVA DE INGRESSO EM ESTABELECIMENTO PRISIONAL. REVISTA VEXATÓRIA. ILICITUDE DA PROVA. ABSOLVIÇÃO. A ré, segundo a denúncia, trazia consigo, para o fim de entrega ao consumo de terceiro, 53,3g de cocaína, na oportunidade em que tentava ingressar na Penitenciária Estadual do Jacuí, para visitar apenado, ocasião em que foi flagrada, durante revista íntima, com a droga inserida no interior da vagina. Após acionado o detector de metais, a ré foi submetida a desnudamento e, procedida à revista íntima, foi retirada, do interior de sua vagina, a droga supramencionada. Ocorrência de revista íntima vexatória. Ofensa à inviolabilidade da intimidade e ao princípio da dignidade da pessoa humana. RECURSO DEFENSIVO PROVIDO, POR MAIORIA. RELATOR VENCIDO. (RIO GRANDE DO SUL, 2019, não paginado).
\end{abstract}

Em menores pode ocorrer a violação de direitos da criança e do adolescente quando em visita aos pais encarcerados. A exigência da revista intima em menores causou conflito com preceitos constitucionais e com o Estatuto da Criança e do Adolescente (ECA), haja vista que violava o Princípio da Dignidade da Pessoa Humana, previsto no artigo 227 da CF que dispõem:

Art. 227. É dever da família, da sociedade e do Estado assegurar à criança, ao adolescente e ao jovem, com absoluta prioridade, o direito à vida, à saúde, à alimentação, à educação, ao lazer, à profissionalização, à cultura, à dignidade, ao respeito, à liberdade e à convivência familiar e comunitária, além de colocá-los a salvo de toda forma de negligência, discriminação, exploração, violência, crueldade e opressão. (BRASIL, 1990, não paginado). 
Já o artigo 18 do Estatuto da Criança e do Adolescente veda qualquer tipo de tratamento desumano, degradante, aterrorizante ou vexatório aos menores impúberes. (BRASIL, 1990).

Quanto aos idosos, temos como previsão legal o Estatuto do Idoso, Lei 10.741/03, que em seu artigo 10, parágrafo 30 prevê: "É dever de todos zelar pela dignidade do idoso, colocando-o a salvo de qualquer tratamento desumano, violento, aterrorizante, vexatório ou constrangedor." (BRASIL, 2003, não paginado).

\section{CONCLUSÃO}

O estudo analisou a existência da violação de Direitos Humanos no sistema carcerário, tanto pela estrutura prisional, como pela conduta dos agentes do estado e de outros presos.

A prisão, que possui como uma de suas vertentes a ressocialização daquele que infringiu as regras da sociedade, embora não seja, deveria ser um ambiente humanizado, com respeito aos direitos fundamentais da pessoa humana.

O condenado é merecedor de respeito pelo Estado e pela sociedade devendo ser assegurado sua proteção de qualquer ato desumano, degradante e de condições precárias, trata-se de um direito fundamental para sua existência. São direitos mínimos e necessários do condenado ter uma condição de vida digna dentro da prisão.

A ONU tem contribuído com vários diplomas legais, tratados e pactos dos quais nosso pais é signatário, os quais possuem o objetivo de proteger o apenado das imoralidades e violações de direitos fundamentais.

As regras estudadas estabelecem que todos os presos devem ser tratados com dignidade e respeito, não podendo ser submetidos a tortura ou tratamento cruel. A pena de privação da liberdade não deve servir para agravar o sofrimento da pessoa presa, vez que um dos objetivos da pena é a reintegração do preso à sociedade.

A harmonização entre direitos humanos e a atuação do agente prisional, só irá ocorrer quando os mesmos se conscientizarem de que eles são garantidores de 
direitos, que devem cumprir e fazer cumprir todas as leis, tratados e convenções de direitos humanos.

A administração penitenciaria deve voltar-se para a desburocratização de seus procedimentos e descentralização de suas ações. 0 modelo deve ser amplo e de maior continuidade, atualizado no mesmo espaço de tempo possível através de trabalhos estratégicos e diagnósticos realizados sobre as ações que envolvem a violentas ações de tortura no país.

Deve haver um melhor aproveitamento das instituições de detenção, deve existir total adequação dessas instituições aos moldes constitucionais do Estado Democrático de Direito atual.

A formação do agente de segurança prisional deve priorizar o juízo moral, de ciências humanísticas e a tecnologia. O currículo para a formação deve abordar conhecimentos técnicos de relacionamento interpessoal, valores éticos, condução rápida de processos de raciocínio e tomada de decisões, todos importantes para que o profissional atue com base na lei e na ordem hierárquica.

É necessário adotar um novo paradigma de capacitação do profissional de segurança, é preciso trabalhar conteúdos e dinâmicas auto referenciadas, o foco primário da formação não deve ser somente sobre o preso, mas sobre o próprio agente e sua forma de relacionar-se consigo, com os outros e com o universo.

A melhor forma para assegurar a defesa dessa garantia é através da participação e controle social junto de ações integradas com outros órgãos, contando ainda com a participação social na fiscalização do trabalho dos presídios junto às ouvidorias e corregedorias.

As organizações da sociedade civil, por sua parte, devem se dedicar a promover ações para ampliar o acesso da população carcerária á justiça, assim como prevenir e controlar o abuso de poder, o uso excessivo da força e a discriminação nas instituições do Sistema de Justiça Criminal.

O respeito por parte dos órgãos de segurança reforça a eficácia da atuação dos próprios profissionais, pois, quando se verifica que a pessoa, mesmo quando presa é protegida, respeitada e tem seus direitos defendidos, a confiança da população no órgão aumenta, o que acaba por contribuir na cooperação entre 
ambos, objetivando a resolução pacífica de conflitos. É necessário um processo abrangente de inclusão social, destacando a importância da solidariedade social com o envolvimento de toda a sociedade, que deve ocorrer através de políticas sociais ativas. É mister ressaltar que a função da sociedade é de extrema importância na ressocialização dos detentos, visto que não seria eficiente a adoção de todas as medidas ressocializadoras e de reintegração do detento à sociedade se a mesma não estiver disposta a oferecer uma nova oportunidade ao ex-detento.

Para que medidas alternativas sejam tomadas e deem certo, se faz necessário a união de sociedade e das autoridades, visto que para a eficácia da ressocialização, o binômio sociedade/autoridade precisa estar alinhado. Somente o investimento das autoridades nas instituições prisionais sem o apoio da sociedade, ou vice-versa, não será suficiente para que o ex-detento se insira novamente na sociedade.

A comunidade deve enxergar os direitos humanos como aliados contra qualquer forma de opressão.

No entanto, antes de executar medidas alternativas deve-se primeiramente respeitar a lei vigente, pois, é através desta a forma correta de manter a ordem e evitar que as penitenciárias sejam uma verdadeira escola para a formação de marginais.

É necessária uma pretensão do Estado para dissociar o indivíduo pobre e negro, morador das periferias da criminalidade, afastando o preconceito e descriminalização.

Os agentes e órgãos de segurança devem ser vistos como parte integrante de uma comunidade, servindo de exemplo de obediência e respeito às leis para outros grupos sociais, levando a uma maior eficácia na prevenção de crimes e violação de direitos.

É importante o uso da ética profissional no sentido de preservar e proteger os direitos humanos, respeitando sempre os princípios da legalidade, necessidade e proporcionalidade. 
Deve haver um fortalecimento institucional para conseguir uma intervenção interdisciplinar coordenada, oportuna e continua através dos diferentes programas que visam garantir o direito do cidadão como pessoa de direitos.

É fundamental o desenvolvimento de ações que busquem a ressocialização dos presos por meio da educação, do trabalho e formação profissional, e outras assistências de natureza reparadora moral, espiritual, social, esportiva e de saúde, visando à melhoria das condições de vida, lembrando que apenas este movimento não basta, mas já é um incentivo. Dar um tratamento digno ao sentenciado diminui as chances de violência dentro dos presídios e diminui a reincidência proporcionando chances ao voltar convívio social. Promover penas alternativas, formação profissional, e permitir o monitoramento eletrônico dos presos já evitaria que o sistema prisional continue em crise.

A própria legislação penal prevê meios para que o preso seja capacitado profissionalmente, permitindo que tenham oportunidade de aprender uma profissão, poder trabalhar, e através do trabalho obter a redução da sua pena, além de tentar mostrar que o trabalho é uma saída para sua sobrevivência, sem que cometa crimes.

Por fim, destaca-se que a capacitação e o treinamento constante dos operadores dos sistemas de Segurança e Justiça são passos imperativos para reduzir o uso abusivo de poder contra o encarcerado, bem como melhora a qualidade do serviço público prestado, e responsabilizar o torturador.

O caminho é extenso e a vigilância há que ser constante, não só por alguns signatários, mas por cada cidadão.

\section{REFERÊNCIAS}

ARAGÃO, Selma Regina. Direitos Humanos: do mundo Antigo ao Brasil de todos. 3. ed. Rio de Janeiro: Forense. 2001.

BITTENCOURT, Cezar Roberto. Tratado de Direito Penal - Parte Geral. 24. ed. São Paulo, Saraiva, 2018. v.1.

BRASIL. Constituição da República Federativa do Brasil de 1988. Brasília, DF: Presidência da República, 1988. Disponível em: http://www.planalto.gov.br/ccivil_03/constituicao/constituicaocompilado.htm. Acesso em: 07 ago. 2019. 
BRASIL. Decreto no 678, de 6 de novembro de 1992. Promulga a Convenção Americana sobre Direitos Humanos (Pacto de São José da Costa Rica), de 22 de novembro de 1969. Brasília, DF: Presidência da República, 1992. Disponível em: http://www.planalto.gov.br/ccivil_03/decreto/d0678.htm. Acesso em: 12 jul. 2019.

BRASIL. Decreto-Lei n⿳0 2.848, de 7 de dezembro de 1940. Código Penal. Rio de Janeiro: Presidência da República, 1940. Disponível em: http://www.planalto.gov.br/ccivil_03/decreto-lei/del2848compilado.htm. Acesso em: 12 ago. 2019.

BRASIL. Lei n. ${ }^{0}$ 7.210 de 11 de julho de 1984. Institui a Lei de Execução Penal. Brasília, DF: Presidência da República, 1984. Disponível em: http://www.planalto.gov.br/ccivil_03/leis/l7210.htm. Acesso em: 24 set. 2019.

BRASIL. Lei nº 8.069, de 13 de julho de 1990. Dispõe sobre o Estatuto da Criança e do Adolescente e dá outras providências. Brasília, DF: Presidência da República, 1990. Disponível em: http://www.planalto.gov.br/ccivil_03/leis//8069.htm. Acesso em: 05 out. 2019.

BRASIL. Lei no 9.455, de 07 de abril de 1997. Define os crimes de tortura, e dá outras providências. Brasília, DF: Presidência da República, 1997. Disponível em: http://www.planalto.gov.br/ccivil_03/leis/L9455.htm. Acesso em: 05 out. 2019.

BRASIL. Lei $\mathbf{n}^{0} \mathbf{1 0 . 7 4 1}$, de $1^{\circ}$ de outubro de 2003. Dispõe sobre o Estatuto do Idoso e dá outras providências. Brasília, DF: Presidência da República, 2003. Disponível em: http://www.planalto.gov.br/ccivil_03/leis/2003//10.741.htm. Acesso em: 05 out. 2019.

BRASIL. Lei $\mathbf{n . ~ 1 3 . 2 7 1 , ~ d e ~} 15$ de abril de 2016. Dispõe sobre a proibição de revista íntima de funcionárias nos locais de trabalho e trata da revista íntima em ambientes prisionais. . Brasília, DF: Presidência da República, 2016. Disponível em: https://planalto.gov.br/ccivil_03/_ato2015-2018/2016/lei/L13271.htm. Acesso em: 24 ago. 2019.

BRASIL. Ministério da Justiça. Levantamento Nacional de Informações Penitenciaria - Infopen Mulheres. Brasília,DF: Departamento Penitenciário Nacional, 2014. Disponível em: https://www.justica.gov.br/news/estudo-traca-perfilda-populacao-penitenciaria-feminina-no-brasil/relatorio-infopen-mulheres.pdf/view. Acesso em: 04 out. 2019.

BRASIL. Ministério da Justiça. Secretaria de Direitos Humanos. Portaria Interministerial no 4.226, de 31 de dezembro de 2010. Brasília, DF: 2011. Disponível em: https://www.conjur.com.br/dl/integra-portaria-ministerial.pdf. Acesso em: 17 ago. 2019. 
BRASIL. Ministério da Justiça e Segurança Pública. Departamento Penitenciário Nacional. Levantamento Nacional de Informações Penitenciarias, atualização junho de 2017. Brasília DF: 2019. Disponível em: http://depen.gov.br/DEPEN/depen/sisdepen/infopen/relatorios-sinteticos/infopenjun-2017-rev-12072019-0721.pdf/view. Data de acesso: 20 out. 2019.

CASTILHO, Ricardo. Direitos Humanos. 2. ed. São Paulo: Saraiva, 2012. (Coleção sinopses jurídicas, 30).

COMPARATO, Fabio Konder. A Afirmação Histórica dos Direitos Humanos. 10. ed. São Paulo: Saraiva. 2010.

CONSELHO NACIONAL DE JUSTIÇA. Regras de Bangkok: Regras das Nações Unidas para o Tratamento de Mulheres Presas e Medidas Não Privativas de Liberdade para Mulheres Infratoras. Brasília, DF: Departamento de Monitoramento e Fiscalização do Sistema Carcerário e do Sistema de Execução de Medidas Socioeducativas, 2016. Disponível em: https://carceraria.org.br/wpcontent/uploads/2018/01/documento-regras-de-bangkok.pdf. Acesso em: 09 out. 2019.

CONSELHO NACIONAL DE POLÍTICA CRIMINAL E PENITENCIÁRIA. Resolução no 14, de 11 de novembro de 1994. Fixa as regras mínimas para o tratamento do preso no Brasil. Brasília, DF: CNPCP, 1994. Disponível em: http://depen.gov.br/DEPEN/depen/cnpcp/resolucoes/1994/resolucaono14de11denov embrode1994.pdf. Acesso em: 14 set. 2019.

GRECO, Rogério. Direitos humanos, sistema prisional e alternativas à privação de liberdade. São Paulo: Saraiva, 2011.

FRIEDE, Reis. Os Direitos Humanos e As Degradantes Prisões Brasileiras. DireitoNet, [S.I.], 26 fev. 2019. Disponível em: https://www.direitonet.com.br/artigos/exibir/11063/Os-direitos-humanos-e-asdegradantes-prisoes-brasileiras. Acesso em: 29 dez. 2019.

KANT, Immanuel. Fundamentação da metafísica dos costumes. Tradução de Paulo Quintela. Lisboa: Edições 70, 2009.

MAHLKE, Helisane. Direitos Humanos. Londrina: Educacional S.A., 2017.

MARIATH, Carlos Roberto. Limites da Revista Corporal no Âmbito do Sistema Penitenciário. 2013. Disponível em:

http://egov.ufsc.br/portal/sites/default/files/anexos/ 13588-13589-1-PB.pdf. Data de acesso: 15 mai 2019.

MIGUEL, Pedro. Você sabe o que é o Cilindro de Ciro? Breves considerações sobre a Primeira Carta de Direitos Humanos reconhecida pela ONU. [S.I], 
2016. Disponível em: https://pedromiiguel.jusbrasil.com.br/artigos/386326597/vocesabe-o-que-e-o-cilindro-de-ciro. Acesso em: 17 jun. 2019.

NUCCI, Guilherme de Souza. Direitos Humanos Versus Segurança Pública. Rio de Janeiro: Forense, 2016.

ORGANIZAÇÃO DAS NAÇÕES UNIDAS. Declaração Universal de Direitos Humanos. Paris: Secretaria da Assembléia-Geral da ONU, 1948. Disponível em: https://unesdoc.unesco.org/ark:/48223/pf0000139423. Acesso em: 23 jul. 2019.

ORGANIZAÇÃO DAS NAÇÕES UNIDAS. Código de Conduta Para os Funcionários Responsáveis Pela Aplicação da Lei. Adotado pela Assembléia Geral das Nações Unidas através da Resolução no 34/169. [S.I.], 1979. Disponível em: http://www.mpsp.mp.br/portal/page/portal/cao_criminal/CAOCri_ControleExtAtivPol/ C\%C3\%B3digo\%20de\%20Conduta\%20para\%20os\%20Funcion\%C3\%A1rios\%20Res pons\%C3\%A1veis\%20pela\%20Aplica\%C3\%A7\%C3\%A30\%20da\%20Lei_2.pdf . Acesso em: 11 nov. 2019.

PARÁ. Procuradoria da República no Pará. MPF recomenda apuração de denúncias de prática de tortura pela Força-Tarefa de Intervenção Penitenciária no PA. Pará, 2019. Disponível em: http://www.mpf.mp.br/pa/salade-imprensa/noticias-pa/mpf-recomenda-apuracao-de-denuncias-de-pratica-detortura-pela- forca-tarefa-de-intervencao-penitenciaria-no-pa. Acesso em: 28 nov. 2019.

PAULA, Ana Carolina Medeiros Costa; SANTANA, Isael José. Mulheres: A Violação dos Direitos Fundamentais por Meio da Revista Íntima. Revista LEVS, [S.I], n. 9, 2012. Disponível em:

http://www2.marilia.unesp.br/revistas/index.php/levs/article/view/2291. Acesso em: 2 jul. 2019.

PERRI, Orlando. Calabouço Medieval: Déficit de agentes gera instabilidade em presídios de MT, diz desembargador. Revista Consultor Jurídico, [S.I], 26 nov. 2019. Disponível em: https://www.conjur.com.br/2019-nov-26/deficit-agentes-geraincerteza-presidios-mt-desembargador. Acesso em: 28 nov. 2019.

PIOVESAN, Flávia. Temas de Direitos Humanos. São Paulo: Saraiva, 2014.

RABESCHINI, André Gomes. Lei de Tortura: Lei no 9.455/97. Boletim Jurídico, Uberaba, ano 13, n. 1218, dez. 2014. Disponível em:

https://www.boletimjuridico.com.br/doutrina/artigo/3906/lei-tortura-lei-n-945597\#sobre. Acesso em: 15 nov. 2019.

RIO DE JANEIRO (Estado). Lei n. 7.010, de 26 de maio de 2015. Dispõe sobre o sistema de revista de visitantes nos estabelecimentos prisionais do Rio de Janeiro e dá outras providências. Rio de Janeiro: Assembleia Legislativa do Estado do Rio de Janeiro, 2015. Disponível em: https://gov- 
rj.jusbrasil.com.br/legislacao/191596255/lei-7010-15-rio-de-janeiro-rj. Acesso em: 13 ago. 2019.

RIO GRANDE DO SUL. Tribunal de Justiça. Terceira Câmara Criminal. Apelação Crime no 70080578297. Relator: Sérgio Miguel Achutti Blattes, 17 de abril de 2019. Disponível em: https://tj-

rs.jusbrasil.com.br/jurisprudencia/708600721/apelacao-crime-acr-70080578297rs?ref=serp. Acesso em: 20 out. 2019.

SÃO PAULO (Estado). Lei n. 15.552, de 12 de agosto de 2014. Proíbe a revista íntima dos visitantes nos estabelecimentos prisionais e dá outras providências. São Paulo: Assembleia Legislativa do estado de São Paulo, 2014. Disponível em: https://www.al.sp.gov.br/repositorio/legislacao/lei/2014/lei-15552-12.08.2014.html. Acesso em: 26 jun. 2019.

SARLET, Ingo Wolfgang. A eficácia dos direitos fundamentais. 10. ed. Porto Alegre: Livraria do Advogado, 2011.

SARLET, Ingo Wolfgang. Dignidade (da Pessoa) Humana e Direitos

Fundamentais na Constituição Federal de 1988. 10. ed. Rev. Atual. e ampl. Porto Alegre: Livraria do Advogado Editora, 2015.

SILVA, Renata Custódio de Oliveira Domingueti. Os Direitos Fundamentais na Constituição Federal: Evolução Histórica e Dimensões. Âmbito Jurídico, Rio Grande, v. 20, n. 160, maio 2017. Disponível em: http://ambitojuridico.com.br/site/?n_link=revista_artigos_leitura\&artigo_id=18902. Acesso em: 21 ago. 2019.

SOARES, Ikaro Luan Porto; MELLO, Anaína Clara de. A Ressocialização do Preso Frente ao Sistema Penitenciário Brasileiro. Revista Brasileira de Direito Penal, João Pessoa, ano I, n. 1, jun. 2016. Disponível em:

http://www.rbdp.com.br/artigos/01/03.html. Acesso em: 18 nov. 2019.

Recebido em 12/02/2019.

Aceito em 07/04/2019. 